\title{
Understanding the Relationship between Preschool Teachers' Well-Being, Interaction Quality and Students' Well-Being
}

\author{
Marigen Narea ${ }^{1,2}$ (D) Ernesto Treviño ${ }^{2,3} \cdot$ Alejandra Caqueo-Urízar $^{4}$. \\ Catalina Miranda ${ }^{2}$ - Javiera Gutiérrez-Rioseco ${ }^{2}$
}

Accepted: 6 November 2021 /Published online: 23 November 2021

(c) The Author(s), under exclusive licence to Springer Nature B.V. 2021

\begin{abstract}
A substantial body of research shows that teacher-student interactions have a significant impact on student outcomes. However, to our knowledge, less is known about the association between teachers' and students' well-being and the implications for teacher-child interactions, particularly in the preschool context. Research Findings. Using ordinary least squares regression, we investigated the association between affective balance and burnout among 28 preschool teachers and the emotional and behavioral problems of 593 students between three and four years old. We found that teacher affective balance-not teacher burnout-was associated with fewer emotional and behavioral problems in children. Furthermore, the different domains of interaction quality affected children's well-being in different ways. Practice or Policy. In initial teacher training and continuing professional development, teachers should be provided with support and strategies to help them manage their mental health and children well-being. Some interventions which have shown encouraging results are discussed.
\end{abstract}

Keywords Classroom quality $\cdot$ Teacher well-being $\cdot$ Emotional problems · Behavioral problems $\cdot$ Preschool

Marigen Narea

mnarea@uc.cl

1 Escuela de Psicología, Pontificia Universidad Católica de Chile, Avda. Vicuña Mackenna 4860, Macul, Santiago, Chile

2 Centro de Estudios Avanzados en Justicia Educacional (CJE), Pontificia Universidad Católica de Chile, Santiago, Chile

3 Facultad de Educación, Pontificia Universidad Católica de Chile, Santiago, Chile

4 Instituto de Alta Investigación, Universidad de Tarapacá, Arica, Chile 


\section{Introduction}

Well-being has become a central topic in education and a crucial indicator with specific goals for international organizations for year 2030 (OECD, 2019). In the case of early childhood education, this topic is even more relevant due to the crucial opportunity to support social, emotional, and cognitive skills during this period of life (Immordino-Yang et al., 2019). In this sensitive developmental period, high-quality early childhood education (ECE) has been associated with important future benefits for children, especially those living in poverty (Ansari \& Winsler, 2012; Brooks-Gunn et al., 2016; Schmerse, 2020; Yoshikawa et al., 2013). Various studies have suggested that classroom interactions between teachers and students are key to promoting cognitive (Whittaker et al., 2020), emotional, and social development (Blewitt et al., 2020; Thorpe et al, 2020) among children in ECE (Hamre \& Pianta, 2001; Mortensen \& Barnett, 2015; Spilt et al., 2015).

Creating well-being supportive environments is related to the quality of relationships between teachers and students. Recent research has suggested an important link between teachers' and children's well-being in school (Lavy \& NaamaGhanayim, 2020), especially in ECE (Harding et al., 2019; Rusby et al., 2013). Positive teacher-student relationships support the mental health of children and young people (Kidger et al., 2012; Plenty et al., 2014) and improve students' well-being (Aldridge \& McChesney, 2018). For example, supportive teacher-student relationships are associated with lower rates of student depression (Kidger et al., 2012; Plenty et al., 2014).

Also, the literature suggests a relationship between teacher and students' wellbeing in the ECE classrooms. For example teachers exhibiting an optimist mood positively contributed to caregiving behaviors and children well-being (De Schipper et al., 2008). Also teachers stress is correlated with a greater frequency of behavioral problems in children and fewer positive responses to children's behavior (Rusby et al., 2013). Furthermore, teacher burnout predicted school readiness, inhibitory control, and behavioral problems in children of preschool age in Colombia (Bernal \& Ferro n.d.). More recent research shows that the relationship between the well-being of teachers and children appears to be bidirectional. For example, Jeon et al. (2019) found that higher levels of anxiety and lower levels of social competence in children predicted higher levels of accumulated work stress in teachers. Also, teachers show higher stress when they perceive more behavioral problems in children (Friedman-Krauss et al., 2014). In sum, teachers need to be emotionally available in order to implement stimulating interactions (Aikens et al., 2015; Montgomery \& Rupp, 2005).

There is a large body of research on teacher-child interactions and, to a lesser extent, the associations between teachers' and children's well-being and the implications for teacher-child interactions. To gain a better understanding of this association, the aim of this study is to investigate the relationship between two aspects of teachers' well-being-namely, emotional balance and burnout, the quality of teacher-child interactions and children's well-being. 


\subsection{Well-Being in Preschool Teachers and Children}

Recent evidence suggests an association between early childhood teachers' wellbeing and their capacity to provide high-quality education, a situation that has renewed the interest in teachers' well-being (Cumming, 2017). Research on the well-being of early childhood teachers shows that it is scarce (Hall-Kenyon et al., 2014), highly fragmented, and uses a wide range of instruments to measure teachers' well-being (Cumming, 2017; Hall-Kenyon et al., 2014). In this study, we use a broad approach to teachers' subjective well-being considering specifically emotional balance and burnout. Subjective well-being involves feeling good and positively judging life, thinking the affective component related to positive and negative emotions (Diener et al., 1985; Ryan \& Deci, 2001). In this sense, wellbeing can deteriorate due to stress, understood as a dynamic process between the individual and their environment, in which the individual faces a circumstance that exceeds her or his ability to handle it - usually determined by the personal resources of the individual (Lazarus \& Folkman, 1984).

Burnout is a key category within the concept of stress. It occurs in a work context in which complex social relationships take place-such as the role of careand it is associated with the concept of one's own self vis-à-vis that of others (Maslach, 1993). Burnout has been studied from a multidimensional perspective and includes three elements. First, emotional exhaustion, the most basic aspect of burnout, refers to the feeling of being strongly overwhelmed by emotions and feeling that one's emotional resources have been exhausted. Second, depersonalization usually includes the loss of ideals, refers to a cynical, negative, or excessively detached response toward people. It usually develops due to efforts to adapt to emotional exhaustion and corresponds to the interpersonal dimension. Finally, reduced personal fulfillment, related to self-assessment (Maslach, 1993), is characterized by a decrease in the perception of competence and productivity at work and has been associated with depression and an inability to face work demands.

Complementarily to teachers' well-being, behavioral and emotional problems during infancy and childhood can affect individuals throughout their adolescence and adulthood (Rutter et al., 2006). Furthermore, severe behavioral problems in childhood show a moderate to strong continuation in the life cycle, especially in the context of family dysfunction (Campbell et al., 2000). Lyons-Ruth et al. (2017) argue that, globally, at least $16 \%$ of children from birth to four years old are diagnosed with a emotional disorder such as anxiety or depression or behavioral problems, such as impulsivity or disruptive behavior. Early identification of emotional and behavioral problems is important to optimize children's future development and learning (Jones et al., 2008, 2015).

Teachers face the challenge of addressing children's emotional and behavioral issues within preschool classrooms through their pedagogical interactions. Positively dealing with these issues is critical for children's well-being. It has implications in the long run for self-esteem, prosocial behavior, school attendance, and an increased risk of unhealthy behaviors such as substance abuse, smoking, delinquency, and suicidal behavior (Novak \& Mihic, 2018). 
Understanding the relationship between teacher well-being, classroom interactions, and children's well-being is crucial to support positive education and life trajectories, as the literature suggests. Furthermore, after the COVID-19 pandemic, children's well-being is at stake due to both the lack of opportunities for socialization due to preschool closures (Cost et al., 2021).

\subsection{Quality Interactions in Preschool Education}

Early preschool relationships and interactions can contribute to children's longterm academic, social, and emotional success (Hamre \& Pianta, 2001; O'Connor \& McCartney, 2007; Schmerse, 2020). According to Bronfenbrenner and Morris' (2006) bioecological model, proximal processes (i.e., regular interactions with parents or teachers) are central drivers of children's development. Based on the bioecological model and other theoretical research, the Teaching through Interactions (TTI) framework conceptualizes teachers' and children's interactions into three domains: emotional support, classroom organization, and instructional support (Hamre et al., 2013).

Emotional support encompasses teachers' efforts at supporting the social and emotional functioning of children, creating a welcoming atmosphere, fostering the relationship between children, revealing knowledge about each child, and providing individualized attention. All of this creates a sense of security and relationship, which allows exploration and motivates learning (Downer et al., 2010; Hamre et al., 2012, 2013). Classroom organization emphasizes the use of proactive strategies for classroom management and is aimed at promoting the development of children's self-regulation (Downer et al., 2010; Hamre et al., 2012, 2013). Finally, instructional support entails interactions that encourage the use of complex thinking, provide opportunities to apply prior knowledge to new situations, limit learning to real contexts, model the use of language, etc. (Downer et al., 2010; Hamre et al., 2012, 2013).

In this regard, classroom interactions related to emotional support can promote socioemotional development among children (Blewitt et al., 2020). However, unbalanced interactions with a strong emphasis mainly on instructional support can intensify problems in the relationship between teachers and students (Domínguez et al., 2011). Teachers can contribute to children's emotional well-being children by facilitating early detection; promoting structured, predictable, and stimulating environments; modeling adaptive thoughts and behaviors; and providing strategies and explicit instruction in skills such as monitoring mood, teaching adaptive styles of thinking, and proposing mastery experiences (Stormont et al., 2015). In the same vein, primary education classrooms that provide a high degree of emotional support to students tend to attenuate students' internalized behavior, and in classrooms that couple emotional support and classroom organization show a positive relationship with students' externalizing behaviors (Griggs et al., 2016). Furthermore, enhancing behavioral management in the classroom is related to reductions in behavioral problems among children (Vancraeyveldt et al., 2014). Similarly, increasing individual interactions with children who are at risk of displaying behavioral problems reduces 
these problems, especially in classrooms characterized by lower-quality interactions (Williford et al., 2017). Finally, social interactions with greater guidance from the teacher are associated with lower levels of externalized behavior than social interactions with less teacher guidance (Roubinov et al., 2020).

\subsection{Teacher Well-Being and Classroom Interactions}

Recent studies show a relationship between the psychological well-being of teachers and the variables inherent to the classroom. For example, the greater the depressive symptomatology of teachers, the lower the quality of interactions in terms of class organization and instructional support in preschool classroom (Sandilos et al., 2015). One study tested the relationship between the three dimensions of classroom interaction and the stress associated with teaching duties and work commitment (Penttinen et al., 2020), finding that teacher stress is inversely related to emotional support, class organization, and instructional support, while work commitment was positively associated with instructional support. Bernal \& Ferro (n.d.), observed that burnout interfered with the quality of interactions, leading to interactions characterized by less warmth and sensitivity.

Essentially, teacher well-being is positively associated with student well-being. It is negatively related to student psychological distress, suggesting that the quality of the teacher-student interactions is at the core of these associations (Harding et al., 2019). Following these notions, this paper studies the relationship between teacher and student well-being in preschool classrooms. As far as we know, this relationship has not previously been examined. Also, this article explores how the quality of classroom interactions affects the well-being of children.

\section{Method}

\subsection{Participants}

The study utilized data from preschool teachers and children attending the higher secondary level of publicly run kindergartens in the Arica y Parinacota and Metropolitan regions of Chile. The study used a non-probabilistic cluster sample, where a total of 28 classrooms were selected: nine at establishments in the Arica y Parinacota region and 19 at establishments in the Metropolitan region. With regard to the participants, information was obtained from 593 children, but we analyzed the responses of 573 children and 28 teachers. Although we effectively began working with 573 cases, as variables were incorporated into the analysis, the number of observations decreased. As such, we ran Little's MCAR test, which allowed us to confirm that the missing data were indeed random (without patterns). We obtained a $p$-value of 0.047 , indicating that the missing data showed random behavior $(\mathrm{Li}$, 2013).

For the child participants, we considered their age, gender, and year of entry into kindergarten (start of education). With regard to the parents, we recorded the 
educational level reached by the mother, and finally, we recorded the age of the teachers. The children had an average age of 47 months and had mostly started their education at one $(31.8 \%)$ or two $(28.5 \%)$ years of age, with only $17.2 \%$ of them entering kindergarten at the age of four. Furthermore, $47 \%$ of them were male and $53 \%$ female. With respect to the educational level of the mother, we found that the majority had completed secondary school (42.6\%) or higher education $(42.9 \%)$ and that only $14.5 \%$ had not completed school education. Finally, the teachers participating in the study were 38 years old on average (Table 1).

\subsection{Variables and Instruments}

\subsubsection{Children's Well-Being}

We measured the dimension of children's well-being using the Child and Adolescent Evaluation System (SENA (the Spanish acronym)), a comprehensive, multi-source, and multidimensional assessment battery aimed at identifying the main emotional and behavioral problems in children and adolescents from three to 18 years of age (Fernández-Pinto et al., 2015). The index of emotional problems summarizes the internalized problems of children, that is, emotional alterations typical of anxiety and depression disorders. Internalized problems are defined as a group of emotional symptoms that mainly involve inner distress of the individual; they reveal a greater frequency of efforts to control behavior, feelings associated with sadness, low selfesteem, inhibition of behavior, and fear (Novak \& Mihic, 2018).

Meanwhile, the index of behavioral problems involves externalized problems experienced by children, which cause conflicts in interactions with other children. Externalized problems represent behavior patterns marked by impulsivity, disruptive behavior, and substance use (Achenbach et al., 2016; Vieira et al., 2018). In both indices, the scores are standardized $(X=0 ; \mathrm{SD}=1)$ and refer to the responses reported by the preschool or classroom teacher.

Table 1 Descriptives of Socioeconomic Variables

\begin{tabular}{lcccll}
\hline Variables & N & Average & SD & Min & Max \\
\hline Students by school & 593 & 21.18 & 4.96 & 1 & 28 \\
Child & 593 & 0.47 & 0.50 & 0 & 1 \\
Age of children (months) & 555 & 47.10 & 4.86 & 26 & 66 \\
Start of education (1 year) & 557 & 0.32 & 0.47 & 0 & 1 \\
Start of education (2 years) & 557 & 0.29 & 0.45 & 0 & 1 \\
Start of education (3 years) & 557 & 0.22 & 0.42 & 0 & 1 \\
Start of education (4 years) & 557 & 0.17 & 0.38 & 0 & 1 \\
School level incomplete & 484 & 0.15 & 0.35 & 0 & 1 \\
Secondary School level & 484 & 0.43 & 0.50 & 0 & 1 \\
Higher education & 484 & 0.43 & 0.50 & 0 & 1 \\
Age of teachers (years) & 28 & 38.19 & 9.11 & 25 & 59 \\
\hline
\end{tabular}

The education level of the mother and the start of education are included in the analysis as dichotomous variables 


\subsubsection{Teacher Well-Being}

Teacher well-being was measured through the Positive and Negative Affect Schedule (PANAS), which measures affective balance, and the Maslach Burnout Inventory - Human Services Survey (MBI-HSS), which measures burnout. Affective balance is constructed based on PANAS, which contains two self-reporting scales: one for positive affect (the degree to which a person feels enthusiastic, active, and alert) and the other for negative affect (moods, such as anger, contempt, disgust, guilt) (Watson et al., 1988), with affective balance being the result of the difference between positive and negative affect.

The Burnout scale is also self-reported and measures the discomfort associated with work variables. This scale encompasses emotional exhaustion, depersonalization (cold or distant attitudes), and personal fulfillment (feelings of selfefficacy and job fulfillment).

\subsubsection{Quality of Teacher-Child Interactions}

We used the Classroom Assessment Scoring System (CLASS Toddler) instrument (Pianta et al., 2008) to assess the quality of the interactions in the classroom. This instrument provides overall ratings of classroom interactions for the following three dimensions: instructional support (development of concepts, quality of feedback, and linguistic modeling), emotional support (positive climate, negative climate, teacher sensitivity, and regard for student perspectives), and classroom organization (behavior management, productivity, and learning formats). These dimensions are measured on a scale from 1 to 7 (where 7 is the highest score), after which they are averaged by domain (Yoshikawa et al., 2015). This instrument has previously been used in Chile (Gebauer \& Narea, 2021).

The classroom record involved recording a four-hour educational day, taking into account several classroom phenomena: instructional activities, transitions, breaks, and meals. After obtaining the audiovisual record, four segments were coded for each classroom of activities, each with a duration of $20 \mathrm{~min}$, which were coded remotely by certified technical staff. With respect to the consistency in the CLASS coding, we obtained a Kappa coefficient of 0.924.

Finally, three sociodemographic variables were used as controls: the mother's educational level (school level incomplete, school level complete, and higher education), the child's age in months, and the start of education, which is the age at which the student entered the preschool $(1,2,3$, or 4 years of age).

\subsection{Procedure}

Eight steps were applied to complete the study: 
1. Approval was obtained from the Ethics Committee of the Pontificia Universidad Católica de Chile.

2. Approval was obtained from the Legal Department of the Junta Nacional de Jardines Infantiles (National Kindergartens Board).

3. Nine educational establishments in the Arica y Parinacota region were invited to participate, all of which accepted. In the Metropolitan region, 21 educational establishments were invited, of which 19 agreed to participate, totaling 28 educational establishments or $93.3 \%$ of those invited.

4. After explaining the purpose and scope of the study, consent was requested from all the parents of all participating children. The informed consent of the teachers who participated was also obtained in the same way.

5. The assessments of the families were carried out in three stages. In the first stage, proxy meetings were held, in which instructions and individualized support were provided when required. These meetings lasted approximately $45 \mathrm{~min}$. Later, the families who did not attend were contacted in person or by telephone to schedule a time. Finally, in the event of unavailability, the protocols were sent to their home, along with specific instructions, which were later collected.

6. The classroom team were assisted by interviewers trained on the instrument. A large proportion of the instruments was carried out together in order to ensure the necessary feedback. Once the team had acquired a degree of familiarity with the SENA instrument, they were given certain protocols to complete themselves, with the assurance that the interviewers were available to answer their questions.

7. Once the reporting instruments were obtained, recordings were made for the CLASS instrument.

8. The entire fieldwork process was carried out between September 2019 and January 2020.

\subsection{Analysis Plan}

In order to examine the determinants impacting students' emotional and behavioral problems, we performed an ordinal least square (OLS) regression, with robust standard errors (Acock, 2014) specifying the classrooms as a cluster. In addition, for an appropriate and significant comparison of the coefficients and relative weights of the models (Agresti, 2018), we standardized the scores of the scales of the well-being of the children, the quality of the interaction in the classroom, and the well-being of the teachers. These analyses were carried out using the STATA 14 statistical software.

\section{Results}

Table 2 shows the descriptive statistics for the well-being of the children (emotional problems and behavioral problems). With respect to the emotional problems reported by the team in the classroom, on average, they reached 47 points and increased in relation to behavioral problems, which reached an average of 52 points. Both indicators were in a low-risk zone (scores lower than 6 points), while the index 
Table 2 Descriptives of Children's Well-being

\begin{tabular}{llllll}
\hline Variables & $\mathrm{N}$ & Average & $\mathrm{SD}$ & Min & Max \\
\hline Index of emotional problems & 573 & 47.03 & 10.57 & 34 & 96 \\
Index of behavioral problems & 572 & 52.19 & 14.52 & 42 & 112 \\
\hline
\end{tabular}

of behavioral problems veered closely toward the precautionary zone (equal to or greater than 60 and lower than 70).

Table 3 presents the distribution of the well-being indicators for the teachers (affective balance and burnout) and classroom (CLASS-T). With regard to the wellbeing of the teachers, the average score for affective balance was 23.6 points (scored from 10 to 50) and, for burnout, 0.90 (on average, some times a year, they feel discomfort at work).

Regarding classroom interactions, both emotional support and class organization were in the medium-high range. The results showed that the domain of emotional support reached the highest average score in the classrooms observed, putting them at a medium-high level with a score of 5.29. Nevertheless, the classrooms recorded an average score of 2.49 in the instructional support domain, showing a low-medium level of performance. The average result of the three domains was 4.18, which is a medium level.

In order to analyze the association between the well-being of the teachers and that of the children, we carried out separate analyses according to the well-being indicators of the teachers, affective balance, the emotional and behavioral problems of the children, the teachers' burnout, and the emotional and behavioral problems of the children.

Table 4 shows the regression of the association between the affective balance of the teachers and the emotional and behavioral problems of the children. The results of the analysis indicate that better affective balance among the teachers was linked to a reduction in both emotional problems, such as anxiety and depression $(p<0.05)$, and behavioral problems $(p<0.01)$ among the children.

Furthermore, in relation to the children, when controlling for the affective balance predictor, we observed that the better the organization of the class, the lower the children's emotional problems $(p<0.01)$. In contrast, greater instructional support was associated with more emotional problems among the children $(0.20$; $p<0.05)$. Further, among the children who participated in the study, we found

Table 3 Descriptives of Well-being of Teachers and CLASS

\begin{tabular}{llcccc}
\hline Variables & N & Average & SD & Min & Max \\
\hline Affective balance & 28 & 23.64 & 6.87 & 5 & 40 \\
Burnout & 28 & 0.90 & 0.45 & 0.06 & 1.86 \\
Emotional support domain (CLASS) & 28 & 5.29 & 0.62 & 4.31 & 6.50 \\
Class organization domain (CLASS) & 28 & 4.75 & 0.84 & 2.83 & 6.58 \\
Instructional support domain (CLASS) & 28 & 2.49 & 0.66 & 1.58 & 4.00 \\
\hline
\end{tabular}


Table 4 Emotional and Behavioral Problems and Affective Balance among Teachers

\begin{tabular}{|c|c|c|c|c|c|c|c|c|}
\hline & \multicolumn{4}{|c|}{ Emotional problem } & \multicolumn{4}{|c|}{ Behavioral problems } \\
\hline & Model 1 & Model 2 & Model 3 & Model 4 & Model 1 & Model 2 & Model 3 & Model 4 \\
\hline Intercept & $\begin{array}{l}0.00 \\
(0.09)\end{array}$ & $\begin{array}{l}0.08 \\
(0.17)\end{array}$ & $\begin{array}{l}1.06 \\
(0.57)\end{array}$ & $\begin{array}{l}1.29 * \\
(0.55)\end{array}$ & $\begin{array}{l}0.00 \\
(0.05)\end{array}$ & $\begin{array}{l}-0.11 \\
(0.11)\end{array}$ & $\begin{array}{l}0.58 \\
(0.41)\end{array}$ & $\begin{array}{l}0.53 \\
(0.40)\end{array}$ \\
\hline Affective balance & $\begin{array}{l}-0.18 * \\
(0.08)\end{array}$ & $\begin{array}{l}-0.19 * \\
(0.08)\end{array}$ & $\begin{array}{l}-0.18^{*} \\
(0.08)\end{array}$ & $\begin{array}{l}-0.20 * \\
(0.07)\end{array}$ & $\begin{array}{l}-0.16^{* * *} \\
(0.04)\end{array}$ & $\begin{array}{l}-0.18 * * \\
(0.04)\end{array}$ & $\begin{array}{l}-0.18^{* *} \\
(0.03)\end{array}$ & $\begin{array}{l}-0.16^{* *} \\
(0.04)\end{array}$ \\
\hline Emotional support & $\begin{array}{l}0.28 \sim \\
(0.14)\end{array}$ & $\begin{array}{l}0.22 \\
(0.13)\end{array}$ & $\begin{array}{l}0.22 \\
(0.12)\end{array}$ & $\begin{array}{l}0.20 \\
(0.12)\end{array}$ & $\begin{array}{l}0.19 * \\
(0.07)\end{array}$ & $\begin{array}{l}0.12 \\
(0.08)\end{array}$ & $\begin{array}{l}0.11 \\
(0.08)\end{array}$ & $\begin{array}{l}0.13 \\
(0.08)\end{array}$ \\
\hline Class organization & $\begin{array}{l}-0.44 * * \\
(0.12)\end{array}$ & $\begin{array}{l}-0.42 * * \\
(0.11)\end{array}$ & $\begin{array}{l}-0.44 * * \\
(0.10)\end{array}$ & $\begin{array}{l}-0.41 * * \\
(0.10)\end{array}$ & $\begin{array}{l}-0.15 \\
(0.09)\end{array}$ & $\begin{array}{l}-0.09 \\
(0.08)\end{array}$ & $\begin{array}{l}-0.10 \\
(0.07)\end{array}$ & $\begin{array}{l}-0.10 \\
(0.08)\end{array}$ \\
\hline Instructional support & $\begin{array}{l}0.15 \\
(0.09)\end{array}$ & $\begin{array}{l}0.19 \\
(0.10)\end{array}$ & $\begin{array}{l}0.20^{*} \\
(0.09)\end{array}$ & $\begin{array}{l}0.20 * \\
(0.09)\end{array}$ & $\begin{array}{l}-0.00 \\
(0.07)\end{array}$ & $\begin{array}{l}0.00 \\
(0.09)\end{array}$ & $\begin{array}{l}0.02 \\
(0.08)\end{array}$ & $\begin{array}{l}0.01 \\
(0.08)\end{array}$ \\
\hline \multicolumn{9}{|c|}{ Educational level of mother* } \\
\hline $\begin{array}{l}\text { School level } \\
\text { complete }\end{array}$ & & $\begin{array}{l}-0.09 \\
(0.15)\end{array}$ & $\begin{array}{l}-0.11 \\
(0.15)\end{array}$ & $\begin{array}{l}-0.16 \\
(0.17)\end{array}$ & & $\begin{array}{l}-0.17 \\
(0.12)\end{array}$ & $\begin{array}{l}-0.16 \\
(0.12)\end{array}$ & $\begin{array}{l}-0.11 \\
(0.12)\end{array}$ \\
\hline Higher education & & $\begin{array}{l}-0.20 \\
(0.14)\end{array}$ & $\begin{array}{l}-0.23 \\
(0.14)\end{array}$ & $\begin{array}{l}-0.25 \\
(0.14)\end{array}$ & & $\begin{array}{l}-0.13 \\
(0.12)\end{array}$ & $\begin{array}{l}-0.11 \\
(0.12)\end{array}$ & $\begin{array}{l}-0.07 \\
(0.12)\end{array}$ \\
\hline Gender $^{* *}$ & & $\begin{array}{l}0.04 \\
(0.07)\end{array}$ & $\begin{array}{l}0.05 \\
(0.07)\end{array}$ & $\begin{array}{l}0.09 \\
(0.07)\end{array}$ & & $\begin{array}{l}0.53^{* *} \\
(0.10)\end{array}$ & $\begin{array}{l}0.52^{* *} \\
(0.10)\end{array}$ & $\begin{array}{l}0.51^{* *} \\
(0.10)\end{array}$ \\
\hline Age of child (months) & & & $\begin{array}{l}-0.02 \\
(0.01)\end{array}$ & $\begin{array}{l}-0.02 \\
(0.01)\end{array}$ & & & $\begin{array}{l}-0.02 \\
(0.01)\end{array}$ & $\begin{array}{l}-0.02 \\
(0.01)\end{array}$ \\
\hline \multicolumn{9}{|c|}{ Start of child's education ${ }^{* * *}$} \\
\hline 1 year & & & & $\begin{array}{l}-0.34 * \\
(0.12)\end{array}$ & & & & $\begin{array}{l}-0.14 \\
(-0.10)\end{array}$ \\
\hline 2 years & & & & $\begin{array}{l}-0.28 \\
(0.16)\end{array}$ & & & & $\begin{array}{l}0.12 \\
(-0.11)\end{array}$ \\
\hline 3 years & & & & $\begin{array}{l}0.03 \\
(0.18)\end{array}$ & & & & $\begin{array}{l}0.05 \\
(-0.13)\end{array}$ \\
\hline Number of obs & 573 & 469 & 463 & 460 & 573 & 468 & 462 & 459 \\
\hline $\mathrm{R}^{2}$ & 0.11 & 0.12 & 0.14 & 0.16 & 0.04 & 0.12 & 0.12 & 0.12 \\
\hline
\end{tabular}

Robust standard errors in parentheses

$\sim p=0.05, * p<0.05 ; * * p<0.01 *$ reference category school level incomplete; **reference category female; $* * *$ reference category 4 years

that the lower their age, the lower their emotional problems $(-0.34 ; p<0.05)$. Meanwhile, boys showed more behavioral problems than girls $(p<0.01)$.

With regard to the burnout among the teachers and the index of emotional and behavioral problems among the children, generally speaking, no statistically significant association between these variables was observed. Only in one scenario did we find that an increase in the work discomfort of the teachers increased the behavioral problems experienced by the children $(0.13 ; p<0.05)$. 


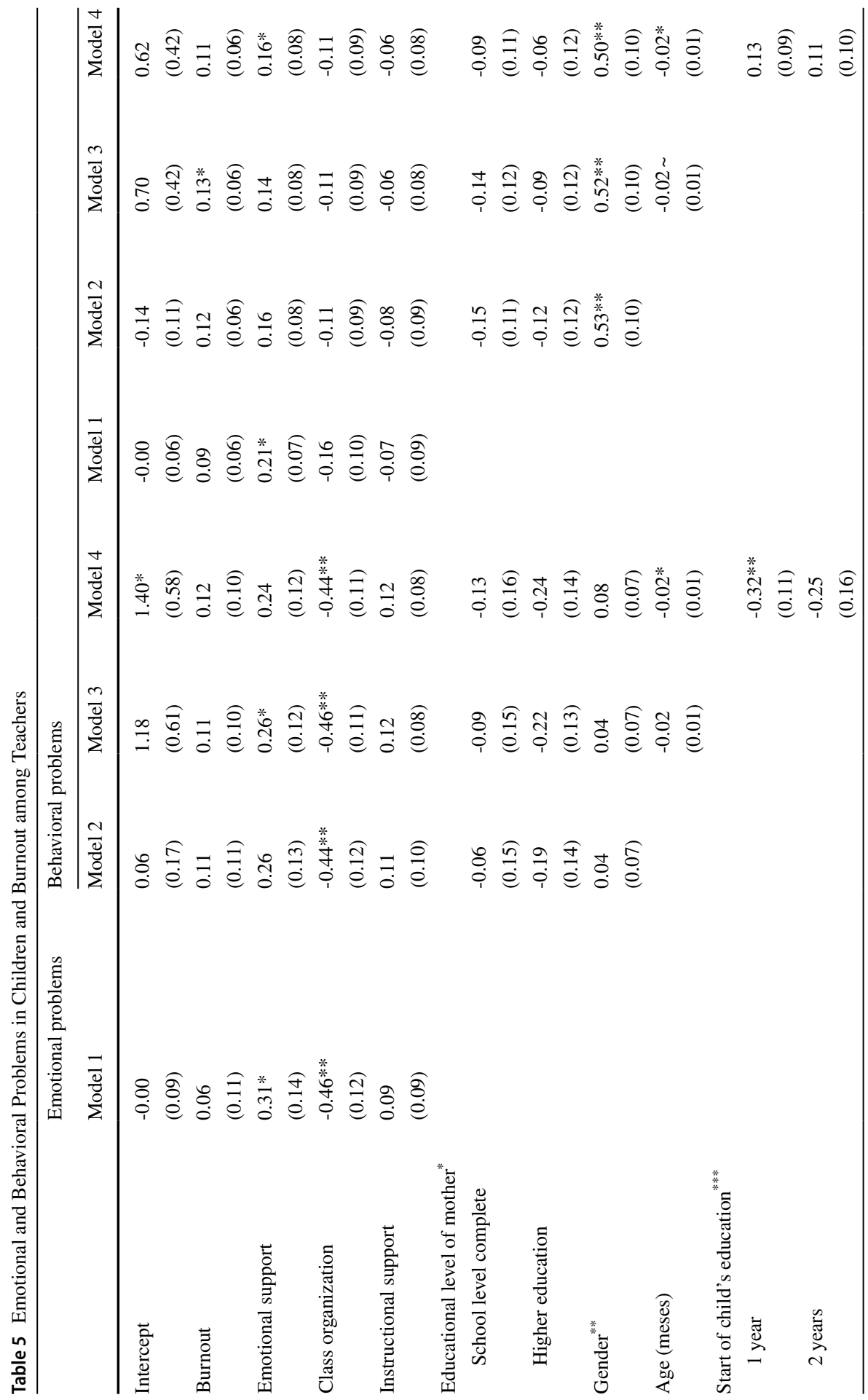




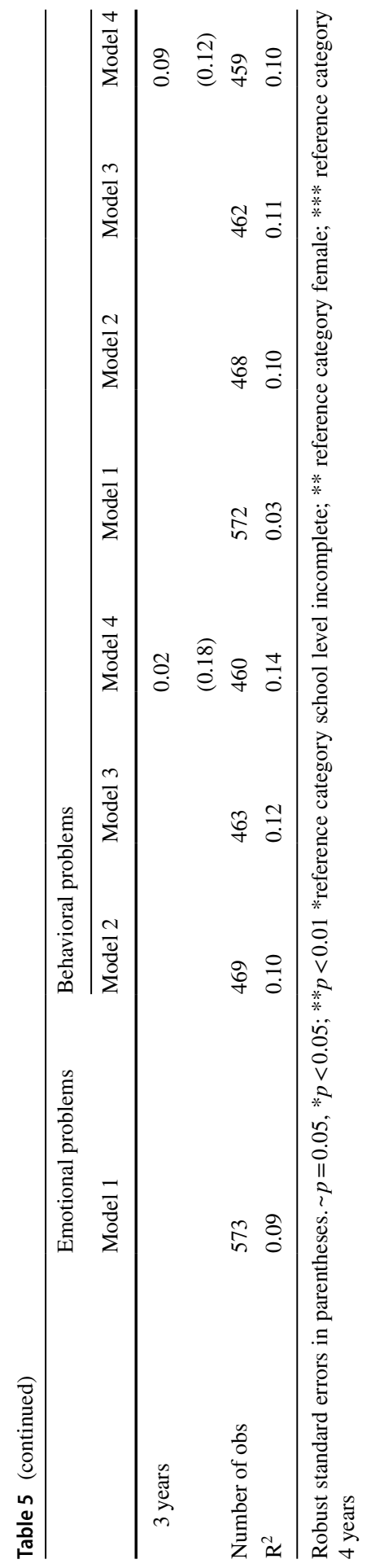

글 Springer 
Table 5 shows that the greater the emotional problems among the children, the greater the emotional support in the classroom $(p<0.05)$, with this association varying in the estimated models. Class organization was a positive variable for decreasing emotional problems $(p<0.01)$, while instructional support did not have a significant association with emotional problems. Among the characterization variables, we found that starting preschool education early (at 1 year) reduced the likelihood of emotional problems, as older children showed fewer emotional and behavioral problems $(p<0.05)$. Finally, boys displayed more behavioral problems than girls $(p<0.01)$.

\section{Discussion}

The literature contends that children learned more when their teacher was happy and performing well (Glazzard \& Rose, 2019). In this study, we wanted to extend the literature by studying whether students were better off when their teachers were happy. For this reason, we intended to describe the association between the wellbeing of teachers - measured as affective balance and burnout-and the emotional and behavioral problems in children ages three and four years. Additionally, following the bioecological theory (Bronfenbrenner \& Morris, 2006), we also sought to understand how the quality of the interactions in the classroom affected student well-being because regular interactions of children with teachers (proximal processes) are central drivers of children's well-being.

First, we can say that the affective balance of the teachers, and not their burnout, was associated with emotional and behavioral problems among the children. Specifically, insofar as the teacher had greater affective balance, that is, more positive than negative feelings, the children tended to show fewer emotional and behavioral problems. This is in line with the finding of De Schipper et al. (2008), that the positive mood and optimism of teachers contributed positively to children's well-being. In contrast, our finding of no association between burnout and emotional and behavioral problems in children was contrary to the evidence (Bernal \& Ferro, n.d.; Friedman-Krauss et al., 2014; Jeon et al., 2019), which may have been due to the fact that burnout levels in this sample were not high and did not show much variability.

After controlling for both affective balance and burnout among the teachers, we also observed that greater class organization was related to fewer emotional problems in children. Class organization emphasizes the use of proactive strategies for classroom management to promote the development of self-regulation among children. Griggs et al. (2016) observed that classes with a high level of organization had a positive impact on externalized behavior (behavioral problems). Conversely, in this study, class organization was related to emotional problems (internalizing behavior).

Furthermore, we also observed that more emotional support was associated with greater levels of behavioral and emotional problems in children, educator burnout, and behavioral problems in the case of affective balance. These findings are not consistent with the evidence, which shows that greater emotional support in the classroom was associated with a decrease in internalized (emotional problems) and externalized (behavioral problems) behaviors (Griggs et al., 2016). 
Finally, the greater the instructional support, the more emotional problems were observed in the case of affective balance. This relationship supports the hypothesis that greater levels of emotional problems correspond with more instructional support. In other words, as there are children with emotional problems in the classroom, the teachers interact with them through instructional practices to include them. These results lead us to believe that the well-being of educational staff should be an important focus of preschools and schools.

Based in our results and program evaluation evidence, we believe that it is crucial that policymakers and the educational system jointly consider the emotional needs of teachers and children when designing early childhood interventions and teacher professional development programs to promote them to provide adequate support for teachers and students that may need it.

Importantly, in initial teacher training, as well as in continuing professional development, teachers should be provided with support and strategies to help them manage their own well-being and increase their resilience. Furthermore, it should be taken into account that there is a risk in adopting an individualistic programmatic approach and that it is essential to have a broader emphasis on relationships, pedagogy, and community building, all of which are central to the development of emotional well-being in teachers.

There are some teacher professional development programs for early childhood teachers that have been shown to be effective at improving teacher well-being and classroom quality after a year (Wolf et al., 2019). However, the positive results, such as reductions in teacher burnout, faded after two years and that there were no positive results across any of the indicators of professional well-being (Wolf \& Peele, 2019). This highlights that teacher well-being cannot easily be changed.

In addition, some interventions have shown encouraging results regarding the importance of improving classroom interactions with the aim of impacting the well-being of children. For example, the Playing 2-gether program-which sought to reduce behavioral problems through the quality of relationships between the child and teacher and strengthen behavioral management in the classroom-managed to reduce levels of behavioral problems and decrease conflict in these relationships (Vancraeyveldt et al., 2014). Similarly, the Banking Time intervention, based on attachment theory, reinforced sensitive and responsive interactions between a teacher and a particular child. A randomized study showed that increasing individual interactions with children who are at risk of showing behavioral problems reduced these problems and decreased negative interactions with these children. This intervention had a greater impact in classrooms that displayed lower-quality interactions (Williford et al., 2017).

\subsection{Limitations and Future Research}

First, the number of classrooms $(n=28)$ did not allow us to carry out a hierarchical regression analysis or to test a mediation model, which would have enabled us to observe how the quality of interactions in the classroom mediated the association between the well-being of the teachers and that of the children. Second, the 
directionality of the association could not be studied with our design. We know that the association can be bidirectional, so it is essential to carry out a longitudinal study in future research. A longitudinal design will permit us to explore whether some of the results of our research that do not go in the direction of previous evidence can be explained by our cross-sectional design that does not allow us to explore the directionality of the associations.

Third, the measurements did not consider contextual measures that could have helped us contextualize the well-being of the educators, specifically in terms of understanding that their well-being was not only individual but also influenced by contextual factors of the workplace. Therefore, in future research, it would be useful to be able to incorporate variables such as working conditions and the systems that shape teachers' well-being.

Finally, following the evidence that interventions can improve both the quality of interactions and the well-being of teachers and children (Vancraeyveldt et al., 2014; Williford et al., 2017; Wolf \& Peele, 2019), it is necessary to have future studies that implement and evaluate these interventions in different contexts.

\section{Conclusions}

This study focused on the relationship between teacher and children well-being, and the quality of classroom interactions in preschool. The evidence suggests a positive relationship between teacher and children well-being, which is also associated with positive and supportive classroom interactions.

Our conclusions point out the need for a more systemic understanding of how teachers and children's well-being play out during classroom interactions. This means the classroom is not a vacuum that extracts the socioemotional well-being of teachers and students. On the contrary, it seems necessary to carefully consider how the crossing of the well-being of the two main classroom factors may influence the quality of interactions. Although teacher and children well-being are essential phenomena in themselves, we need to understand their intersection further when the act of socialization in preschool classrooms take place.

Finally, this is the first approximation to this topic and further research is needed to both confirm the relationships found in this study and deepen our comprehension of a phenomenon that may require greater attention after the COVID-19 pandemic that has increased the mental and socioemotional problems across the population. This is particularly important for children in preschool age, because of the window of opportunity to promote positive interactions and support long-life learning and socioemotional development.

Acknowledgements We thank Junta Nacional de Jardines Infantiles (JUNJI) and our team of research assistants for their invaluable collaboration.

Funding This article was funded by ANID PIA CIE160007 and FONIDE 181800208.

Availability of Data and Material The datasets generated during and/or analysed during the current study are available from the corresponding author on reasonable request. 


\section{Declarations}

Code Availability (Software Application or Custom Code) Not applicable' for that section.

\section{Ethical Approval}

This study was approved by the Ethics Committee of the Pontificia Universidad Católica de Chile.

Consent to Participate Informed consent was obtained from all individual participants included in the study.

Consent for publication Not applicable.

Competing of Interest The authors declare that they have no competing interests.

\section{References}

Achenbach, T. M., Ivanova, M. Y., Rescorla, L. A., Turner, L. V., \& Althoff, R. R. (2016). Internalizing/ externalizing problems: Review and recommendations for clinical and research applications. Journal of the American Academy of Child and Adolescent Psychiatry, 55(8), 647-656. https://doi.org/ 10.1016/j.jaac.2016.05.012

Acock, A. C. (2014). A gentle introduction to Stata. College Station.

Agresti, A. (2018). An introduction to categorical data analysis. Wiley.

Aikens, N., Xue, Y., Bandel, E., Caronongan, P., Vogel, C. A., \& Boller, K. (2015). Early head start home visits and classrooms: Stability, predictors, and thresholds of quality. OPRE Brief 2015-34. Office of Planning, Research and Evaluation, Administration for Children and Families.

Aldridge, J. M., \& McChesney, K. (2018). The relationships between school climate and adolescent mental health and wellbeing: A systematic literature review. International Journal of Educational Research, 88, 121-145. https://doi.org/10.1016/j.ijer.2018.01.012

Ansari, A., \& Winsler, A. (2012). School readiness among low-income, Latino children attending family childcare versus centre-based care. Early Child Development and Care, 182(11), 1465-1485. https://doi.org/10.1080/03004430.2011.622755

Bernal, R., \& Ferro, M. (n.d.). The effects of teacher mental health and job burnout on child development. https://doi.org/10.1017/CBO9781107415324.004

Blewitt, C., O’Connor, A., Morris, H., Mousa, A., Bergmeier, H., Nolan, A., Jackson, K., Barrett, H., \& Skouteris, H. (2020). Do curriculum-based social and emotional learning programs in early childhood education and care strengthen teacher outcomes? A systematic literature review. International Journal of Environmental Research and Public Health, 17(3), 1049. https://doi.org/10.3390/IJERP H17031049

Bronfenbrenner, U., \& Morris, P. A. (2006). The Bioecological Model of Human Development. In R. M. Lerner \& W. Damon (Eds.), Handbook of child psychology: Theoretical models of human development (pp. 793-828). Wiley.

Brooks-Gunn, J., Markman-Pithers, L., \& Rouse, C. E. (2016). Starting early: Introducing the issue. Future of Children, 26(2), 3-20. https://doi.org/10.1353/foc.2016.0009

Campbell, S. B., Shaw, D. S., \& Gilliom, M. (2000). Early externalizing behavior problems: Toddlers and preschoolers at risk for later mal-adjustment. Development and Psychopathology, 12(3), 467-488. https://doi.org/10.1017/s0954579400003114

Cost, K. T., Crosbie, J., Anagnostou, E., Birken, C. S., Charach, A., Monga, S., Kelley, E., Nicolson, R., Maguire, J. L., Burton, C. L., Schachar, R. J., Arnold, P. D., \& Korczak, D. J. (2021). Mostly worse, occasionally better: impact of COVID-19 pandemic on the mental health of Canadian children and adolescents. European child \& adolescent psychiatry, 1-14. Advance online publication. https://doi. org/10.1007/s00787-021-01744-3

Cumming, T. (2017). Early childhood educators' well-being: An updated review of the literature. Early Childhood Education Journal, 45(5), 583-593. https://doi.org/10.1007/s10643-016-0818-6 
De Schipper, E. J., Riksen-Walraven, J. M., Geurts, S. A. E., \& Derksen, J. J. L. (2008). General mood of professional caregivers in child care centers and the quality of caregiver-child interactions. Journal of Research in Personality, 42, 515-526. https://doi.org/10.1016/j.jrp.2007.07.009

Diener, E., Emmons, R. A., Larsen, R. J., \& Griffin, S. (1985). The satisfaction with life scale. Journal of Personality Assessment, 49(1), 71-75. https://doi.org/10.1093/brain/84.1.1

Domínguez, X., Vitiello, V. E., Fuccillo, J. M., Greenfield, D. B., \& Bulotsky-Shearer, R. J. (2011). The role of context in preschool learning: A multilevel examination of the contribution of context-specific problem behaviors and classroom process quality to low-income children's approaches to learning. Journal of School Psychology, 49(2), 175-195. https://doi.org/10.1016/j.jsp.2010.11.002

Downer, J. T., Sabol, T. J., \& Hamre, B. (2010). Teacher-child interactions in the classroom: Toward a theory of within- and cross-domain links to children's developmental outcomes. Early Education \& Development, 21(5), 699-723. https://doi.org/10.1080/10409289.2010.497453

Fernández-Pinto, I., Santamaría, P., Sánchez-Sánchez, F., Carrasco, M. A., \& del Barrio, V. (2015). SENA. Sistema de Evaluación de Niños y Adolescentes. Manuel de aplicación, corrección e interpretación. TEA Ediciones.

Friedman-Krauss, A. H., Raver, C. C., Neuspiel, J. M., \& Kinsel, J. (2014). Child behavior problems, teacher executive functions, and teacher stress in head start classrooms. Early Education and Development, 25(5), 681-702. https://doi.org/10.1080/10409289.2013.825190

Gebauer, A. \& Narea, M. (2021) Calidad de las interacciones entre agentes educativas y niños/as que asisten a nivel medio menor en Jardines Infantiles públicos de la Región Metropolitana, y su relación con características de las agentes educativas y de las aulas. Psykhe.

Glazzard, J., \& Rose, A. (2019). The impact of teacher well-being and mental health on pupil progress in primary schools. Journal of Public Mental Health, 19(4), 349-357. https://doi.org/10.1108/ JPMH-02-2019-0023

Griggs, M., Mikami, A. Y., \& Rimm-Kaufman, S. E. (2016). Classroom quality and student behavior trajectories in elementary school. Psychology in the Schools, 53(7), 690-704. https://doi.org/10.1002/ pits. 21941

Hall-Kenyon, K., Robert, B., MacKay, K., \& Marshall, E. (2014). Preschool teacher well-being: A review of the literature. Early Childhood Education Journal, 42, 153-162. https://doi.org/10.1007/ s10643-013-0595-4

Hamre, B. K., \& Pianta, R. (2001). Early teacher - child relationships and the trajectory of children's school outcomes through eighth grade. Child Development, 72(2), 625. https://doi.org/10.1111/ 1467-8624.00301

Hamre, B. K., Downer, J. T., Jamil, F. M., \& Pianta, R. C. (2012). Enhancing teachers' intentional use of effective interactions with children: Designing and testing professional development interventions. In R. Pianta (Ed.), Handbook of early childhood education (pp. 507-532). Guilford Press.

Hamre, B. K., Pianta, R. C., Downer, J. T., DeCoster, J., Mashburn, A. J., Jones, S. M., Brown, J. L., Cappella, E., Atkins, M., Rivers, S. E., Brackett, M. A., \& Hamagami, A. (2013). Teaching through interactions: Testing a developmental framework of teacher effectiveness in over 4,000 classrooms. The Elementary School Journal, 113(4), 461-487. https://doi.org/10.1086/669616

Harding, S., Morris, R., Gunnella, D., Ford, T., Hollingworth, W., Tilling, K., Evans, R., Bell, S., Grey, J., Brockman, R., Campbell, R., Araya, R., Murphy, S., \& Kidger, J. (2019). Is teachers' mental health and wellbeing associated with students' mental health and wellbeing? Journal of Affective Disorders, 242, 180-187. https://doi.org/10.1016/j.jad.2018.08.080

Immordino-Yang, M. H., Darling-Hammond, L., \& Krone, C. (2019). Nurturing nature: How brain development is inherently social and emotional, and what this means for education. Educational Psychologist, 54(3), 185-204. https://doi.org/10.1080/00461520.2019.1633924

Jeon, L., Buettner, C. K., Grant, A. A., \& Lang, S. N. (2019). Early childhood teachers' stress and children's social, emotional, and behavioral functioning. Journal of Applied Developmental Psychology, 61, 21-32. https://doi.org/10.1016/j.appdev.2018.02.002

Jones, K., Daley, D., Hutchings, J., Bywater, T., \& Eames, C. (2008). Efficacy of the Incredible Years Programme as an early intervention for children with conduct problems and ADHD: long-term follow-up. Child: Care. Health and Development, 34(3), 380-390. https://doi.org/10.1111/j.1365-2214. 2008.00817.x

Jones, D. E., Greenberg, M., \& Crowley, M. (2015). Early social-emotional functioning and public health: The relationship between kindergarten social competence and future wellness. American Journal of Public Health, 105(11), 2283-2290. https://doi.org/10.2105/AJPH.2015.302630 
Kidger, J., Araya, R., Donovan, J., \& Gunnell, D. (2012). The effect of the school environment on the emotional health of adolescents: A systematic review. Pediatrics, 129(5), 925-949. https://doi.org/ 10.1542/peds.2011-2248

Lavy, S., \& Naama-Ghanayim, E. (2020). Why care about caring? Linking teachers' caring and sense of meaning at work with students' self-esteem, well-being, and school engagement. Teaching and Teacher Education, 91, 103046. https://doi.org/10.1016/j.tate.2020.103046

Lazarus, R. S., \& Folkman, S., (1984). Stress, appraisal, and coping. Springer Publishing Company.

Li, C. (2013). Little's test of missing completely at random. The Stata Journal, 13(4), 795-809. https:// doi.org/10.1177/1536867X1301300407

Lyons-Ruth, K., Todd Manly, J., Von Klitzing, K., Tamminen, T., Emde, R., Fitzgerald, H., ... \& Watanabe, H. (2017). The worldwide burden of infant mental and emotional disorder: report of the task force of the world association for infant mental health. Infant Mental Health Journal, 38(6), 695705.https://doi.org/10.1002/imhj.21674

Maslach, C. (1993). Burnout: A multidimensional perspective. In Professional burnout: Recent developments in theory and research (pp. 19-32). https://doi.org/10.4324/9781315227979-3

Montgomery, C., \& Rupp, A. A. (2005). A meta-analysis for exploring the diverse causes and effects of stress in teachers. Canadian Journal of Education, 28(3), 458-486. https://doi.org/10.2307/4126479

Mortensen, J. A., \& Barnett, M. A. (2015). Teacher-child interactions in infant/toddler child care and socioemotional development. Early Education and Development, 26(2), 209-229. https://doi.org/10. 1080/10409289.2015.985878

Novak, M., \& Mihic, J. (2018). Prevention of internalized problems of children and youth in academic setting. In B. Bernal-Morales (Ed.), Health and academic achievement (pp. 123-141). IntechOpen. https://doi.org/10.5772/intechopen.75590

O’Connor, E., \& McCartney, K. (2007). Examining teacher-child relationships and achievement as part of an ecological model of development. American Educational Research Journal, 44, 340-369. https://doi.org/10.3102/0002831207302172

OECD. (2019). OECD Future of Education and Skills 2030: OECD Learning Compass 2030 - A series of concept notes. https://www.oecd.org/education/2030-project/contact/. Accessed 18 Nov 2021

Penttinen, V., Pakarinen, E., von Suchodoletz, A., \& Lerkkanen, M.-K. (2020). Relations between kindergarten teachers' occupational well-being and the quality of teacher-child interactions. Early Education and Development, 1-17. https://doi.org/10.1080/10409289.2020.1785265

Pianta, R. C., La Paro, K. M., \& Hamre, B. K. (2008). Classroom Assessment Scoring SystemTM: Manual K-3. Paul H Brookes Publishing.

Plenty, S., Ostberg, V., Almquist, Y. B., Augustine, L., \& Modin, B. (2014). Psychosocial working conditions: An analysis of emotional symptoms and conduct problems amongst adolescent students. Journal of Adolescence, 37(4), 407-417. https://doi.org/10.1016/j.adolescence.2014.03.008

Roubinov, D. S., Bush, N. R., Hagan, M. J., Thompson, J., \& Boyce, W. T. (2020). Associations between classroom climate and children's externalizing symptoms: The moderating effect of kindergarten children's parasympathetic reactivity. Development and Psychopathology, 32(2), 661-672. https:// doi.org/10.1017/S095457941900052X

Rusby, J., Jones, L., Crowley, R., \& Smolkowski, K. (2013). Associations of caregiver stress with working conditions, caregiving practices, and child behaviour in home-based child care. Early Child Development and Care, 183(11), 1589-1604. https://doi.org/10.1080/03004430.2012.742992

Rutter, M., Kim-Cohen, J., \& Maughan, B. (2006). Continuities and discontinuities in psychopathology between childhood and adult life. Journal of Child Psychology and Psychiatry, 47, 276-295. https:// doi.org/10.1111/j.1469-7610.2006.01614.x

Ryan, R. M., \& Deci, E. L. (2001). On happiness and human potentials: A review of research on hedonic and eudaimonic well-being. Annual Review of Psychology, 52, 141-166. https://doi.org/10.1146/ annurev.psych.52.1.141

Sandilos, L. E., Cycyk, L. M., Hammer, C. S., Sawyer, B. E., López, L., \& Blair, C. (2015). Depression, control, and climate: An examination of factors impacting teaching quality in preschool classrooms. Early Education and Development, 26(8), 1111-1127. https://doi.org/10.1080/10409289.2015. 1027624

Schmerse, D. (2020). Preschool quality effects on learning behavior and later achievement in Germany: Moderation by socioeconomic status. Child Development, 91(6), 2237-2254. https://doi.org/10. 1111/CDEV.13357 
Spilt, J. L., Koomen, H. M. Y., \& Harrison, L. J. (2015). Language development in the early school years: The importance of close relationships with teachers. Developmental Psychology, 51, 185-196. https://doi.org/10.1037/a0038540

Stormont, M., Herman, K. C., \& Reinke, W. M. (2015). The overlooked children: How teachers can support children with internalizing behaviors. Beyond Behavior, 24(2), 39-45. https://doi.org/10.1177/ 107429561502400206

Thorpe, K., Rankin, P., Beatton, T., Houen, S., Sandi, M., Siraj, I., \& Staton, S. (2020). The when and what of measuring ECE quality: Analysis of variation in the Classroom Assessment Scoring System (CLASS) across the ECE day. Early Childhood Research Quarterly, 53, 274-286. https://doi.org/10. 1016/J.ECRESQ.2020.05.003

Vancraeyveldt, C., Verschueren, K., Wouters, S., Van Craeyevelt, S., Van den Noortgate, W., \& Colpin, H. (2014). Improving teacher-child relationship quality and teacher-rated behavioral adjustment amongst externalizing preschoolers: Effects of a two-component intervention. Journal of Abnormal Child Psychology, 43, 243-257. https://doi.org/10.1007/s10802-014-9892-7

Vieira, F., Clanco-Vieira, T., \& Monzani da Rocha, M. (2018). Diagnostic classification systems. In J. M. Matson (Ed.), Handbook of childhood psychopathology and developmental disabilities: Treatment (pp. 97-125). Springer. https://doi.org/10.1007/978-3-319-71210-9_7

Watson, D., Clark, L. A., \& Tellegen, A. (1988). Development and validation of brief measures of positive and negative affect: The PANAS scales. Journal of Personality and Social Psychology, 54(6), 1063-1070. https://doi.org/10.1037/0022-3514.54.6.1063

Williford, A. P., LoCasale-Crouch, J., Whittaker, J. V., DeCoster, J., Hartz, K. A., Carter, L. M., Wolcott, C. S., \& Hatfield, B. E. (2017). Changing teacher-child dyadic interactions to improve preschool children's externalizing behaviors. Child Development, 88(5), 1544-1553. https://doi.org/10.1111/ cdev. 12703

Wolf, S., \& Peele, M. E. (2019). Examining sustained impacts of two teacher professional development programs on professional well-being and classroom practices. Teaching and Teacher Education, 86, 102873. https://doi.org/10.1016/j.tate.2019.07.003

Wolf, S., Aber, J. L., Behrman, J. R., \& Tsinigo, E. (2019). Experimental impacts of the "Quality Preschool for Ghana" interventions on teacher professional well-being, classroom quality, and children's school readiness. Journal of Research on Educational Effectiveness, 12(1), 10-37. https://doi. org/10.1080/19345747.2018.1517199

Whittaker, J. V., Kinzie, M. B., Vitiello, V., DeCoster, J., Mulcahy, C., \& Barton, E. A. (2020). Impacts of an early childhood mathematics and science intervention on teaching practices and child outcomes. Journal of Research on Educational Effectiveness, 13(2), 177-212. https://doi.org/10.1080/19345 747.2019.1710884

Yoshikawa, H., Weiland, C., Brooks-Gunn, J., Burchinal, M. R., Espinosa, L. M., Gormley, W. T., Ludwig, J.; Magnuson, K. A.; Phillips, D.; Zaslow, M. J. (2013). Investing in our future: The evidence base on preschool education. Society for Research in Child Development.

Yoshikawa, H., Leyva, D., Snow, C. E., Treviño, E., Barata, M. C., Weiland, C., Gomez, C. J., Moreno, L., Rolla, A., D'Sa, N., \& Arbour, M. C. (2015). Experimental impacts of a teacher professional development program in Chile on preschool classroom quality and child outcomes. Developmental Psychology, 51(3), 309-322. https://doi.org/10.1037/a0038785

Publisher's Note Springer Nature remains neutral with regard to jurisdictional claims in published maps and institutional affiliations. 